\title{
HESSD
}

\section{Influence of downscaling methods in projecting climate change impact on hydrological extremes of upper Blue Nile basin}

\section{T. Taye and P. Willems}

KU Leuven, Civil Engineering department, Hydraulics Division, Kasteelpark Arenberg 40, 3001 Leuven, Belgium

Received: 5 June 2013 - Accepted: 8 June 2013 - Published: 20 June 2013

Correspondence to: M. T. Taye (meronteferi.taye@bwk.kuleuven.be)

Published by Copernicus Publications on behalf of the European Geosciences Union.

Influence of downscaling

methods on extremes

M. T. Taye and P. Willems

Title Page

Abstract

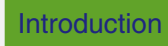

Conclusions

References

Tables

Figures

14

4

Back

Close

Full Screen / Esc

Printer-friendly Version

Interactive Discussion

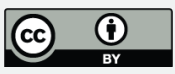




\section{Abstract}

Methods from two statistical downscaling categories were used to investigate the impact of climate change on high rainfall and flow extremes of the upper Blue Nile basin. The main downscaling differences considered were on the rainfall variable while a gen5 erally similar method was applied for temperature. The applied downscaling methods are a stochastic weather generator, LARS-WG, and an advanced change factor method, the Quantile Perturbation Method (QPM). These were applied on $10 \mathrm{GCM}$ runs and two emission scenarios (A1B and B1). The downscaled rainfall and evapotranspiration were input into a calibrated and validated lumped conceptual model. The future simulations were conducted for 2050s and 2090s horizon and were compared with 1980-2000 control period. From the results all downscaling methods agree in projecting increase in temperature for both periods. Nevertheless, the change signal on the rainfall was dependent on the climate model and the downscaling method applied. LARS weather generator was good for monthly statistics although caution has to be taken when it is applied for impact analysis dealing with extremes, as it showed a deviation from the extreme value distribution's tail shape. Contrary, the QPM method was good for extreme cases but only for good quality daily climate model data. The study showed the choice of downscaling method is an important factor to be considered and results based on one downscaling method may not give the full picture. Regardless, the projections on the extreme high flows and the mean main rainy season flow mostly showed a decreasing change signal for both periods. This is either by decreasing rainfall or increasing evapotranspiration depending on the downscaling method.

\section{Introduction}

The upper Blue Nile is one of the river basins in east Africa characterized by high rainfall variability. Arguably the highest impact of this variability happens through extremes, be it floods or extended droughts. The rainfall of this region is modulated by monsoonal
HESSD

10, 7857-7896, 2013

Influence of

downscaling

methods on extremes

M. T. Taye and P. Willems

Title Page

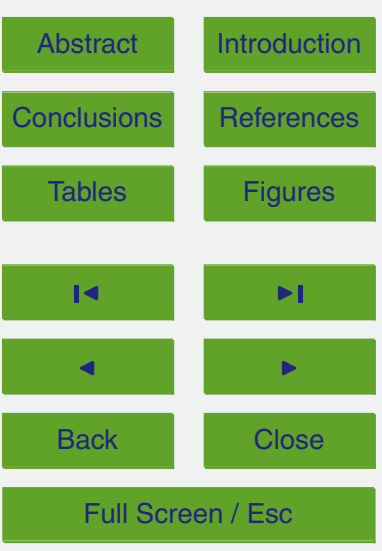

Printer-friendly Version

Interactive Discussion 
climate (Camberlin, 1996; Jury, 2010), large scale atmospheric oscillations such as ENSO (Abtew et al., 2009), changes in the SST or oscillations of Pacific and Atlantic oceans (Diro et al., 2010; Jury, 2010; Taye and Willems, 2012). Additionally the topography of the basin plays a great role (Dinku et al., 2008). These different mechanisms 5 control the rainfall even if the link among them is not entirely understood. Furthermore, since there is high confidence in the continuation of anthropogenic climate change as shown by wide range of scenarios for future greenhouse gas emissions (IPCC, 2012) impact of this change will further complicate rainfall variability. One of the potential impacts of climate change will be in the frequency, intensity and predictability of rainfall. 10 This challenge will ultimately influence water availability in the region which will have far reaching consequences on water supply, agriculture and hydropower generation among others.

Future climate change projections are far from forecasts. Rather they are different probable scenarios that have been constructed based on assumptions about population and world development (IPCC, 2007). These scenarios were run by different institutions using climate or circulation models. The outputs from these models have uncertain change signals. The upper Blue Nile is one of the regions where the rainfall projection is highly uncertain (Setegn et al., 2011; Taye et al., 2011). However, estimating impact of climate change on hydrology typically involves the utilization of climate model outputs from general circulation models (GCM) and/or regional circulation models (RCM) followed by one or more downscaling techniques to finally force hydrological models and obtain future flow projections. By quantifying the difference between the observed/current hydro-meteorological variables and the future projections, it is possible to estimate the probable future impact. Due to the presence of various climate models, emission scenarios, downscaling methods and hydrological models, one has to make a choice which method to utilize for the specific case under study. Consequently, the uncertainty involved in the final outcome is related to the different aspects of the impact study process.

\section{HESSD}

10, 7857-7896, 2013

Influence of

downscaling

methods on extremes

M. T. Taye and P. Willems

Title Page

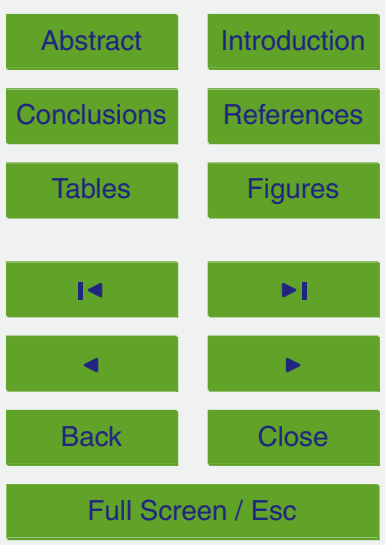

Printer-friendly Version

Interactive Discussion 
Although the climate models are usually held responsible for the high uncertainty, the other aspects of the impact study process should also be investigated for their contribution on the final results. One of these components is the downscaling, the process that ensures to narrow down the scale discrepancy between the coarser scale outputs of the GCMs and the required local scale variables for hydrological modeling. Chen et al. (2011) argues that major sources of uncertainty are linked to GCMs and emission scenarios while uncertainty related but not limited to the choice of a downscaling method have been given less attention. Generally, downscaling techniques are classified into dynamic and statistical downscaling. Dynamic downscaling nests higher 10 resolution RCMs into coarse resolution GCMs to produce complete set of meteorological variables which are consistent with each other. The output from this method is still at a coarser scale compared to what is required locally. Statistical downscaling overcomes this challenge. Extensive details on the strength and weaknesses of both methods can be found in Wilby and Wigley (1997), Wilby and Dawson (2007), 15 Fowler et al. (2007) and Teutschbein et al. (2011) among others. Statistical downscaling is preferred by hydrologists because it is computationally undemanding, flexible and provides the possibility of uncertainty analysis (Wilby et al., 2002). This method has different categories according to the technique applied. For instance, bias correction methods use various algorithms to adjust the GCM outputs and use the corrected data in hydrological models. The delta change (change factor) method transfers the climate model based change signals to the observations and utilizes the perturbed series for further analysis. Stochastic weather generator based method perturbs its parameters according to changes projected by GCMs. The advantage of this method is its ability to rapidly produce sets of climate scenarios for studying the impact of rare climate events

an Other downscaling approaches use empirical transfer functions, regression methods, or weather pattern-based approaches (Willems et al., 2012). Provided that the future is unknown and some of the assumptions cannot be tested, the importance of applying several downscaling methods and comparing the results is undeniable. Such approach was previously applied

\section{HESSD}

10, 7857-7896, 2013

Influence of

downscaling

methods on extremes

M. T. Taye and P. Willems

Title Page

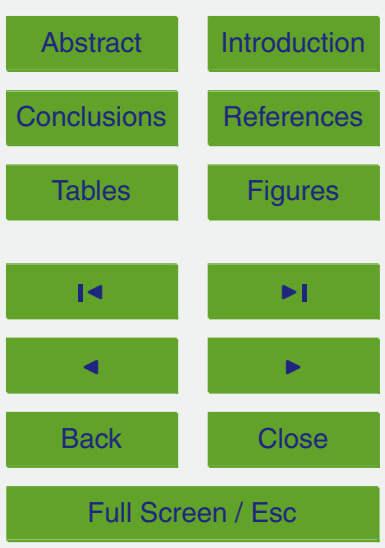

Printer-friendly Version

Interactive Discussion 
by Arnbjerg-Nielsen (2012), Willems and Vrac (2011) and Sunyer et al. (2012) among others.

Among the different possibilities, an example from the change factor method and the stochastic weather generator was chosen with the purpose of comparatively evaluating 5 the methods for quantifying impact of climate change on hydrological extremes. The selected stochastic weather generator is LARS-WG, a public domain and commonly used method. From the change factor category, the more advanced quantile perturbation method (QPM) was selected. Both approaches claim their applicability for extreme conditions which makes them appropriate for this study that focuses on hydrological 10 extremes. Semenov and Stratonovitch (2010) states LARS-WG has been tested in diverse climates and demonstrated a good performance in reproducing various weather statistics including extreme weather events. The QPM, albeit in different versions, was also tested for different regions (Nyeko-Ogiramoi et al., 2010; Taye et al., 2011; Willems and Vrac, 2011; Liu et al., 2011) and was recommended to be applicable for studying extreme events.

The comparison of these downscaling methods was performed for the upper Blue Nile region using ten GCM runs and two emission scenarios (A1B and B1). Previous studies on the Blue Nile region mainly focused on the general hydrology of the basin and most of these studies were conducted using a single downscaling technique, bias correction approaches being the common ones (e.g. Elshamy et al., 2009; Nawaz et al., 2010; Kim and Kaluarachchi, 2009; Beyene et al., 2010) except Ebrahim et al. (2013) who compared three downscaling techniques to assess hydrological impact of climate change in one of the sub-basins of the Blue Nile, the upper Beles basin. Impact analysis that focuses on extremes was conducted for the Lake Tana basin, one of the sub-basins in the Blue Nile (Taye et al., 2011). Therefore, unlike the previous studies, in this paper the entire upper Blue Nile is considered with focus on high rainfall and flow extremes.

Influence of

downscaling

methods on extremes

M. T. Taye and P. Willems

Title Page

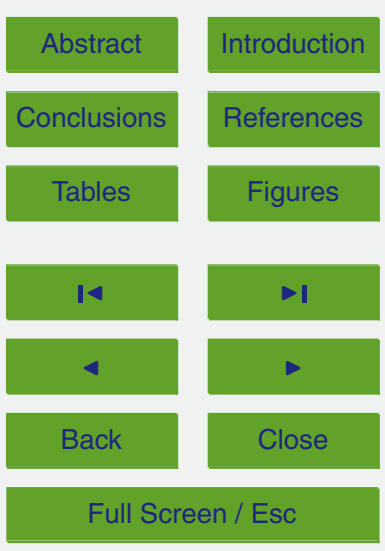

Printer-friendly Version

Interactive Discussion 


\section{Description of study area and data}

\subsection{Study area}

Located in the north-western part of Ethiopia, the upper Blue Nile basin is one of the important river basins in the country covering an area of about $176000 \mathrm{~km}^{2}$. It is the major 5 contributor to the Nile river flow taking the lion's share of more than $60 \%$. The basin is characterized by a complex topography with an elevation range of over $4000 \mathrm{~m}$ in the headwaters and about $500 \mathrm{~m}$ in downstream parts (Fig. 1). The climate in the Blue Nile is governed by north-south seasonal migration of the Inter Tropical Convergence Zone (ITCZ); besides topography significantly influences rainfall patterns although the 10 relationship between rainfall and elevation is not straightforward (Dinku et al., 2008). The basin receives considerable amount of rainfall ranging between 800 and $2200 \mathrm{~mm}$ (Melesse et al., 2010). The largest contribution of this high rainfall occurs during the main rainy season from June to September. The period October to May is usually a prolonged dry period with short rainy season between March and May.

\subsection{Observed data}

Daily observed meteorological data consisting of rainfall, maximum and minimum temperature with relatively good quality from 11 stations was selected and used for this study. The location of the stations is indicated on Fig. 1. These data cover the period 1981-2000 and the missing records were completed using inverse distance weighting method from neighbouring stations. Evapotranspiration (ETo) was calculated using the Hargreaves method. The Hargreaves method although reported to have some limitations in literature compared to the standard FAO Penman-Monteith (PM) method, it is widely used in cases of data limited areas and still provides acceptable results. We compared the daily ETo estimations from the Hargreaves and FAO PM method for the period 1981-2000 and found a strong correlation with correlation coefficient value of 0.99. Since the difference between the two methods was not significant the Hargreaves

Influence of

downscaling

methods on extremes

M. T. Taye and P. Willems

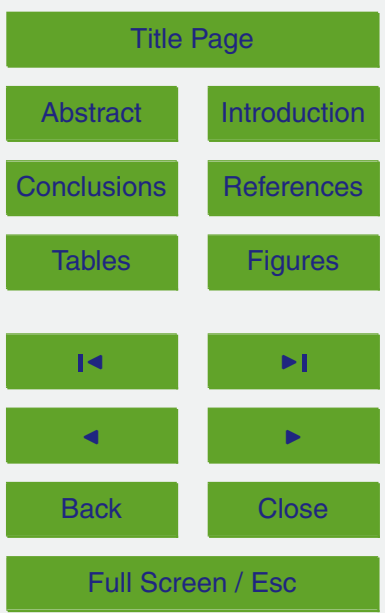

Printer-friendly Version

Interactive Discussion 
method was used for further analysis. This method was also applied in previous studies conducted in the upper Blue Nile basin, for example in Tekleab et al. (2011) and Setegn et al. (2008). To obtain catchment averaged rainfall and evapotranspiration the Thiessen polygon method was used. Discharge data at the outlet of the basin located 5 at the Ethio-Sudanese border (El Diem) is used for comparing with the hydrological simulation results.

\subsection{GCM data}

Daily rainfall and temperature time series from runs with ten different GCMs were obtained from the Program for Climate Model Diagnosis and inter-comparison (PCMDI) 10 database that were used for the Intergovernmental Panel on Climate Change Fourth Assessment Report, 2007. The details of the models are shown in Table 1. The GCMs data considered for this study is for the periods 1981-2000 as control simulations while for the future simulations, two periods were considered: 2049-2065 (2050s) and 20812100 (2090s). Among the IPCC SRES scenarios, A1B and B1 emission scenarios were 15 used for this study.

\section{Description of downscaling methods}

\subsection{Stochastic weather generator}

LARS-WG is a stochastic weather generator that can simulate weather data at a single site under both current and future climate conditions. LARS-WG produces synthetic 20

daily time series of maximum and minimum temperatures, rainfall and solar radiation. The weather generator uses observed daily data for a given site to compute a set of parameters for probability distributions of the variables as well as the correlations between them. The underlining method used to approximate the probability distributions is a semi-empirical distribution (SED) calculated on monthly basis. The computed set of parameters is used to generate synthetic time series of arbitrary length by randomly

\section{HESSD}

10, 7857-7896, 2013

Influence of

downscaling

methods on extremes

M. T. Taye and P. Willems

Title Page

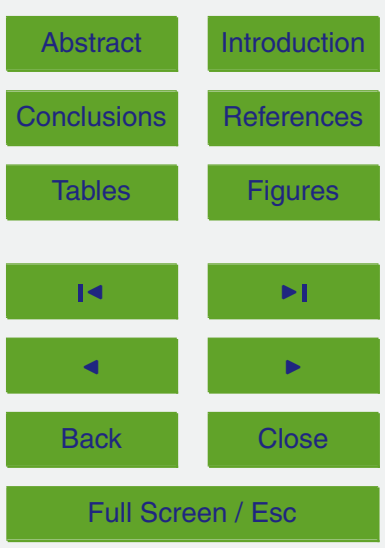

Printer-friendly Version

Interactive Discussion 
selecting values from the appropriate distributions. Afterwards, the parameters of the distributions are perturbed for a site with the predicted monthly changes derived from global climate model runs to finally generate a daily climate scenario of the future for the specific site. The monthly changes are calculated as relative changes for precipi5 tation and radiation and absolute changes for minimum and maximum temperatures. No adjustments for distributions of dry and wet series and temperature variability are made (Semenov and Stratonovitch, 2010).

In LARS-WG the weather generation process is performed in three steps: calibration, validation and climate scenario generation. During calibration it generates synthetic o weather data that corresponds to the observed statistics. This is used to validate the performance of the weather generator by comparing the mean and standard deviation of the observed and the generated data at monthly scale. The generator also provides statistical test results like Kolmogorov-Smirnov, $t$ test and $F$ test for further validation. After validation the program provides the option to generate future scenarios for three

\subsection{Quantile perturbation method}

The Quantile Perturbation Method (QPM) is an example of change factor method dependent on the daily GCM runs data and the observations. The method applies the changes (perturbation factors) obtained from the daily control and scenario quantiles of GCM runs into the observed series in quantile based way. The perturbation factor is the ratio between the scenario simulation quantile and the control simulation quantile with same non-exceedance probability or return period (Nyeko-Ogiramoi et al., 2010). Mathematically, the perturbation factor is obtained as follows. If $X s_{1} \geq X s_{2} \geq X s_{3} \geq$ $\ldots \geq X s_{n}$ represent the scenario quantiles and $X c_{1} \geq X c_{2} \geq X c_{3} \geq \ldots \geq X c_{m}$ repre-

sent the control period quantiles, where $n$ and $m$ are the total number of values in the scenario and control period respectively, the perturbation factors are derived as $X s_{n} / X c_{m}$ for the same return periods. When $n$ and $m$ are not the same interpolation is used to obtain the correct value for a given return period. Note that in our case

\section{HESSD}

10, 7857-7896, 2013

Influence of

downscaling

methods on extremes

M. T. Taye and P. Willems

Title Page

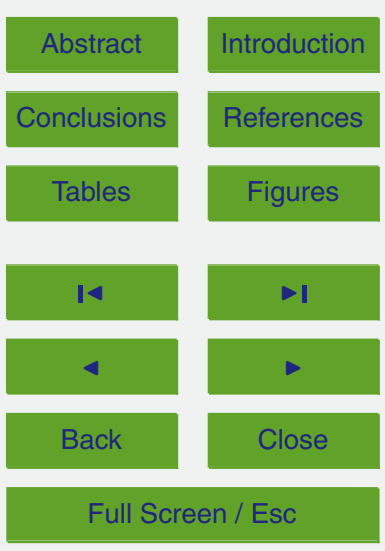

Printer-friendly Version

Interactive Discussion 
the control and future periods are $20 \mathrm{yr}, 1981-2000$ (control), 2045-2065 (2050s) and 2081-2100 (2090s). This makes the $n$ and $m$ to have the same value and no need for interpolation.

Given that the frequency and intensity of rainfall are projected to change, both com5 ponents of the rainfall are perturbed in the QPM approach. Primarily, we give an explanation on the intensity perturbation that includes both relative and absolute changes. The perturbation factors are calculated for each month, this means daily values of a given month from every year considered in the analysis are collected together and arranged in descending order for the next step. The perturbation factors are calculated 10 for the wet days where wet days are defined as any day with rainfall amount greater than a certain threshold value (e.g. $0.1 \mathrm{~mm}$ or $1 \mathrm{~mm}$ ).

The smaller rainfall values that approach to zero when they are multiplied by any number the resulting value will still remain to be small and hence the change will be negligible or if a rainfall value close to zero in the control period is compared to a rainfall value much larger than zero in the scenario period, high perturbation factor is obtained. Application of this high perturbation factor to observed rainfall values may lead to excessive changes, especially when the observed values are systematically higher than the control period values. To address this issue instead of the relative change an absolute change is proposed for rainfall values less than a certain threshold. In this paper 20 we defined a wet day threshold as any day with $0.1 \mathrm{~mm}$ of rainfall. The threshold below which absolute change is applicable is set to be $1 \mathrm{~mm}$. Hence, the relative perturbation factors are applied as in Eq. (1a) and the absolute factors are applied as in Eq. (1b) to the daily observed rainfall values to obtain the future perturbed series. Again the factors are applied to quantiles of the same return periods for each month.

${ }_{25} \quad P_{\text {per }}=P_{\text {obs }} \cdot \frac{P_{\text {sce }}}{P_{\text {con }}} \quad$ for $P_{\text {obs }}>1 \mathrm{~mm}$

$P_{\text {per }}=P_{\text {obs }}+\left(P_{\text {sce }}-P_{\text {con }}\right) \quad$ for $P_{\text {obs }}<1 \mathrm{~mm}$
HESSD

$10,7857-7896,2013$

Influence of

downscaling

methods on extremes

M. T. Taye and P. Willems

Title Page

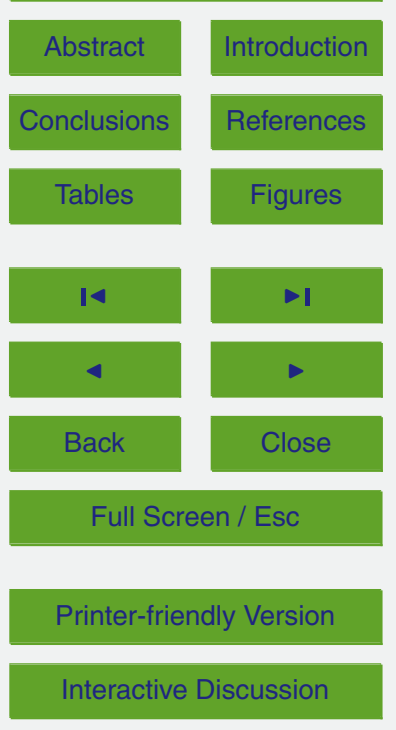


where: $P_{\text {obs }}$ is the observed rainfall, $P_{\text {per }}$ is the perturbed rainfall, $P_{\text {con }}$ is the control period rainfall, $P_{\text {sce }}$ is the scenario period rainfall.

In addition to perturbing the rainfall intensities the frequency is adjusted by adding or removing wet and dry days according to the control and scenario simulation results.

5 This is done after counting and comparing the total number of wet days from the current and future periods for a given month. When wet days are removed the wet days before or after the longest dry spell are changed to dry days and vice versa for adding wet days.

The general flow chart of the QPM downscaling method that accounts for both the 10 intensity and frequency perturbation is as follows

1. Choose a threshold to define wet days and a threshold below which an absolute change is applicable.

2. Count how many daily values are per month for control, scenario and observed series and arrange the daily values per month in descending order.

3. Count number of dry and wet days for control and scenario series and obtain the difference.

4. Add or remove wet days based on step 4 on the observed series.

5. Calculate the relative perturbation factor based on the control and scenario series.

6. Transfer the factor on observed series and obtain the perturbed observed series for values above a given threshold for the relative changes.

7. For values below the threshold, absolute changes are transferred to the observed series.

8. The combination of steps 6 and 7 is the future projection for a given climate model run.

Influence of

downscaling

methods on extremes

\section{T. Taye and P. Willems}

Title Page

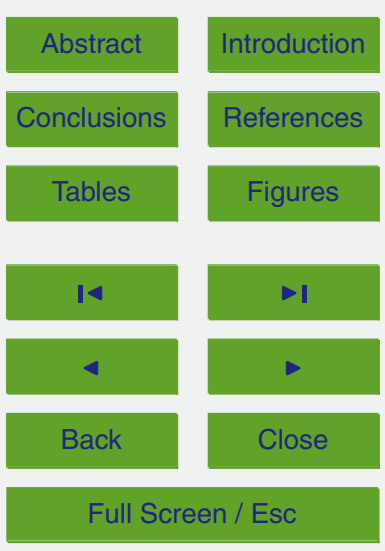

Printer-friendly Version

Interactive Discussion 
The simplest form of the QPM does not consider the addition and removal of wet days. It explicitly considers the perturbation of intensities while that of the frequency is not. This method is also tested next to the advanced method described above.

Temperature has less daily variability compared to rainfall and thus we adopted

5 a simpler perturbation approach that used the temperature difference extracted from the scenario and control series at monthly scale. The perturbation factors (temperature differences) are applied to the observed temperature series as in Eq. (2). This is performed for both maximum and minimum temperature after which evapotranspiration is estimated using these data.

${ }_{10} T_{\text {per }}=T_{\text {obs }}+\left(T_{\text {sce }}-T_{\text {con }}\right)$

where: $T_{\text {obs }}$ is the observed temperature, $T_{\text {per }}$ is the perturbed temperature, $T_{\text {con }}$ is the control period temperature, $T_{\text {sce }}$ is the scenario period temperature.

\section{Performance evaluation of methods}

\subsection{LARS-WG generated data}

The observed daily rainfall and temperature data is used for the calibration and validation of LARS-WG for each station within the upper Blue Nile basin. The validation results show good simulation of the mean monthly rainfall while the standard deviation of the monthly rainfall is not fully captured for most of the stations. The generated mean monthly maximum and minimum temperature match fairly well with the observed values for all the stations. The temperature simulations are better than that of the rainfall.

Since basin-wide rainfall and evapotranspiration data are required for the impact analysis, the performance of LARS-WG generated current (baseline) series is compared with the observed ones after obtaining the basin-wide rainfall. Using the mean monthly values the percentage difference between the two was computed. The result

Influence of

downscaling

methods on extremes

M. T. Taye and P. Willems

Title Page

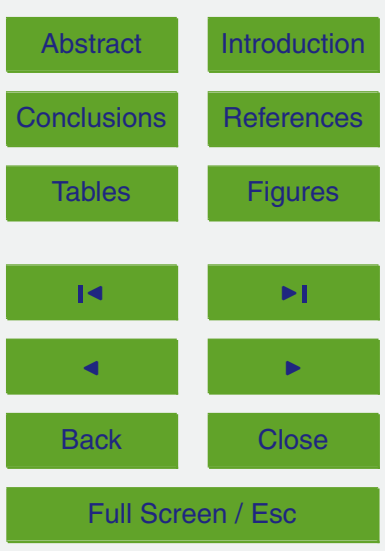

Printer-friendly Version

Interactive Discussion 
shows that LARS-WG generated rainfall has both positive and negative biases. During the dry season, months covering between November and February, there is an overestimation of rainfall values compared to the observation. The month of March is negatively biased while the rest of the rainy season has less than $5 \%$ difference with 5 the observation (Fig. 2).

Additional performance evaluation was conducted for the high intensity values (Fig. 3). This analysis shows the generated data even though it gives a relatively good result at mean monthly scale as shown in Fig. 2 it has a negative bias at daily scale for the high intensities. According to Semenov and Stratonovitch (2010) it is possible to 10 directly use the generated series in impact models. Nevertheless, since the generated data are biased the use of these data in impact models might lead to biased results. A possible solution is to perform bias correction in order to obtain values that are unbiased compared to the observation. A quantile based bias correction was tested in this study by fitting a linear regression equation between the generated and observed data sorted based on their intensities. The correction was implemented for each month separately. After the bias correction the LARS-WG baseline shows good improvement except that the very highest intensities remain slightly underestimated (Fig. 3, red points). Assuming the same bias will be translated to the furture scenario periods, the equations obtained for the current period are used to bias correct the scenario periods generated

\subsection{QPM generated data}

Since the QPM method is dependent on the daily data of the GCMs, it is important to evaluate the performance of the GCM simulations. Hence, the daily rainfall time series obtained from the GCM control simulations were compared with the observation time series for the same $20 \mathrm{yr}$ period. The comparison is done after calculating the basin-wide rainfall from both the observations and the control runs. This analysis was necessary to identify the GCMs with credible data based on how well they follow the seasonality of rainfall. The monthly and annual rainfall statistics such as bias and root

HESSD

10, 7857-7896, 2013

Influence of

downscaling

methods on extremes

M. T. Taye and P. Willems

Title Page

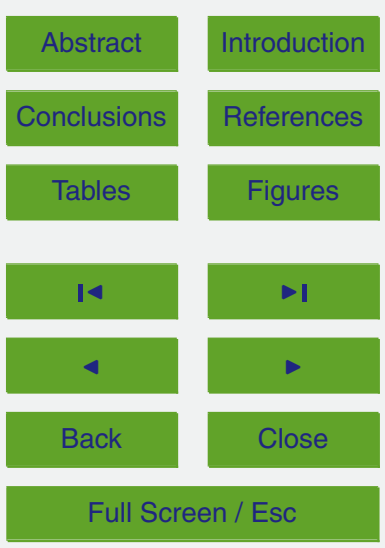

Printer-friendly Version

Interactive Discussion 
mean squared error was also used for the comparison. Among the $10 \mathrm{GCM}$ runs only five of them follow the seasonality of rainfall relatively well. Most of the GCMs have a general negative bias during the wet seasons and a positive bias during the dry seasons (Fig. 4). Five GCMs (MPEH5, CSMK3, GFCM21, INCM3 and MIHR) show 5 poor representation of the seasonality in which they simulate the rainy season as dry season and vice versa.

The poor simulation results of the GCMs is partially expected since what we are comparing is basin-wide rainfall obtained using point rainfall (for the observations) to rainfall obtained from a grid averaged data for the GCMs. On the other hand previous 10 studies (e.g., Elshamy et al., 2009; Nawaz et al., 2010; Zaitchik et al., 2012) showed poor performance of some GCMs for the study area which might mean using these GCMs in the impact analysis introduces larger uncertainties. Assuming the bias in the current and future period is the same and that it will cancel out in the downscaling process, we continued with the QPM approach. After application of the QPM downscaling method on the daily rainfall of the GCM runs the same five GCMs gave extremely high projections for the future. Figure 5 is one example in which the quantiles versus the return periods are shown for the 2050s projection and where one can see those GCM runs give unrealistically high results. We found out that this high projection is due to mismatch in the simulation of the seasons during scenario and control period. That is the wet season in the control period has many dry days and low rainfall values while the scenario period has high values. This difference leads to a high perturbation factor (high rainfall value in scenario period divided by smaller rainfall value in control period) that will be transferred to the observations, and which finally results unrealistically high projections. This was a common feature on the five GCM runs with poor seasonality representation on Fig. 4. For this reason, they were excluded from further analysis.

Similarly, the daily temperature data from the GCMs are compared with the observations at monthly scale as shown in Fig. 6 . The monthly performance reveals that the GCMs are positively biased in simulating both maximum and minimum temperature.

\section{HESSD}

10, 7857-7896, 2013

Influence of

downscaling

methods on extremes

M. T. Taye and P. Willems

Title Page

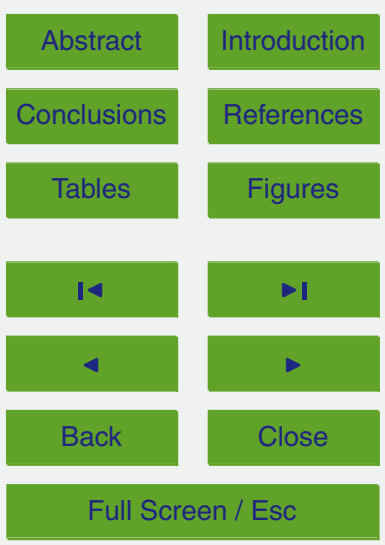

Printer-friendly Version

Interactive Discussion 


\section{Comparison of future projections by the two methods}

Due to the poor performance of daily GCMs that were excluded we remain with five GCMs and two emission scenarios A1B and B1. From the five GCMs, two of them do not have B1 scenario in the LARS-WG generator. Therefore, for the sake of consistency 5 in the next sections we present results from the remaining GCMs with A1B scenario.

\subsection{Rainfall}

Table 2 provides the percentage change of rainfall projections at annual scale. Generally, the mean annual rainfall shows a decreasing projection for the 2050s and 2090s with the exception of one model (CNCM3) after QPM downscaling. In case of LARSWG, the downscaled results project an increase in the mean annual rainfall for both periods. At seasonal scale the main rainy season (JJAS) shows a deceasing projection using QPM for both periods. On the other hand, LARS-WG projections give increasing rainfall except one GCM (CGMR) for the 2090s and a mixed picture for the 2050s. Using QPM downscaling the short rainy season is (MAM) shows a decreasing signal with 15 a percentage more than the main rainy season for all GCM runs. Using LARS-WG both increasing and decreasing rainfall amount is projected. Similar to the QPM results, the percentage change is higher than that of the main rainy season. For the dry season both downscaling methods agree in their projections; they give an increasing signal.

The simplest form of the QPM that does not include adding/removing wet days gives similar monthly change patterns as LARS-WG. Since LARS-WG has no adjustment for the distribution of dry and wet series, similar result obtained from the simpler QPM method is foreseeable. By including the adding/removing component, most of the months showed a decreasing signal while we obtained increasing signal same as LARS-WG using the simpler QPM approach.

25 Since the focus of this study is on extreme cases, it was necessary to look at the daily values. Figure 7 shows the comparison of rainfall distributions of observation and projections for 2050s and 2090s. The main observation from these results is that by
HESSD

10, 7857-7896, 2013

Influence of

downscaling

methods on extremes

M. T. Taye and P. Willems

Title Page

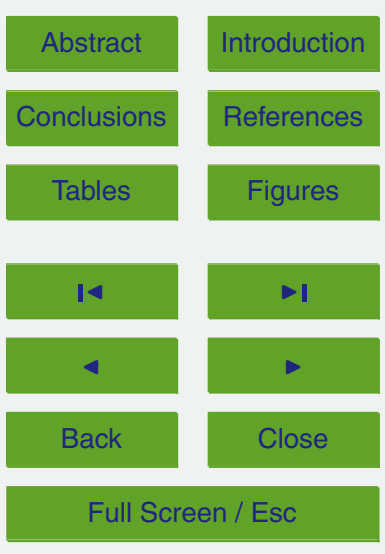

Printer-friendly Version

Interactive Discussion 
using LARS-WG the projections obtained on the higher intensities are lower than those of the projections by the QPM. This shows differences in the extreme value distribution which might result in discrepancies of magnitudes for the higher return period values. The QPM projections have similar distribution as the observations.

\section{$5 \quad 5.2$ Temperature}

For general comparison basin-wide temperature was calculated as the arithmetic average values of all the stations. The mean annual absolute maximum and minimum temperature change between the observed and the projected (perturbed observed) is obtained and presented in Table 4 . On average both maximum and minimum temperatures are projected to increase by $+1{ }^{\circ} \mathrm{C}$ between the 2050s and 2090s. There are slight differences between the change factors used in LARS-WG and what we calculated using the daily data, for example an average increase of $+1.9^{\circ} \mathrm{C}$ by LARS-WG while $+1.6^{\circ} \mathrm{C}$ from the daily GCMs' data between the control period and 2050s. In LARS-WG some of the GCM runs are perturbed using the change in mean temperature, so both maximum and minimum temperatures are perturbed by the same factor. In our case, from the $5 \mathrm{GCMs} 4$ of them were perturbed using this method. Nevertheless, generally the change in minimum temperature is slightly higher than the change in maximum temperature based on the daily GCM's data.

\subsection{Evapotranspiration}

Evapotranspiration is estimated using the downscaled temperature data and compared with the estimation from the observations. Table 5 shows the future projection for evapotranspiration by most of the GCM runs is a positive shift. This is expected considering the warming trend observed in temperature. Although a relatively similar method is used to downscale the temperature, some differences can be seen between the two
HESSD

10, 7857-7896, 2013

Influence of

downscaling

methods on extremes

M. T. Taye and P. Willems

Title Page

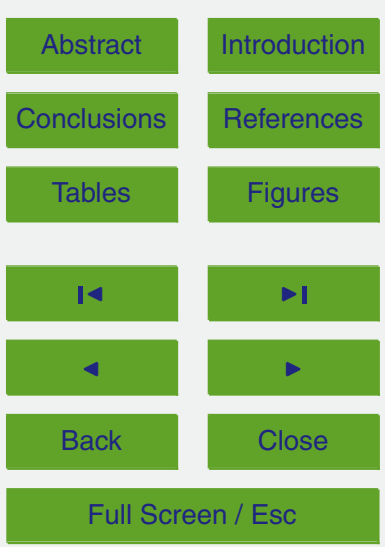

Printer-friendly Version

Interactive Discussion 


\section{Impact analysis on flows}

\subsection{Hydrological model description}

The VHM model, a lumped conceptual model, developed at the Hydraulics Division of the KU Leuven (Willems, 2013) was calibrated and validated to be used for impact

5 analysis. The model constitutes of two main components: the reservoir-based routing and the storage components. The storage components describe water storage in the catchment in the form of surface, root zone/soil and groundwater storage, while the linear reservoirs are used to model the routing of the rainfall contributions to the different runoff subflows. The model structure of VHM is not fixed a priori; rather it is identified in a case-specific manner based on a step-wise procedure. This procedure is data-based using the results of a number of time series pre-processing steps: subflow separation that splits the total flow into subflow components, identification of nearly independent events and extreme high and low flow extraction (Willems, 2009). These results are used to identify relations between the subflow runoff coefficient per event and the relative soil moisture state and/or the antecedent rainfall. The soil moisture state is computed by cumulating the remaining rainfall fractions after evapotranspiration losses and rainfall fractions corresponding to the subflow event volumes are deducted from the total areal catchment rainfall.

Linear or other complex models can be identified and these relations represent submodels describing quick flow, interflow and slow flow volumes. These different volumes are then combined with linear reservoir models to describe the routing of the subflows in which the quick flow fractions are transformed to overland and interflow while the slow flow fraction is transformed to baseflow. Former application of the VHM approach can be found in Liu et al. (2011), Taye et al. (2011), and Van Steenbergen and Willems 25 (2011).

Influence of

downscaling

methods on extremes

M. T. Taye and P. Willems

Title Page

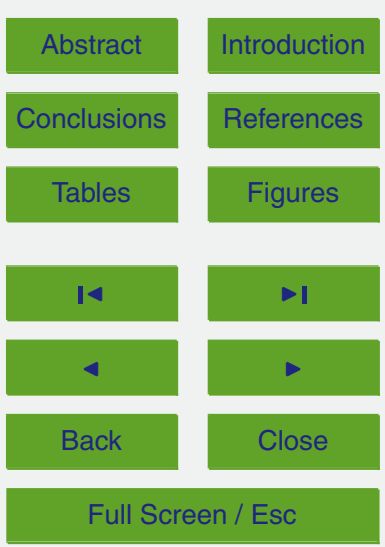

Printer-friendly Version

Interactive Discussion 


\subsection{Upper Blue Nile catchment response}

The downscaled rainfall and evapotranspiration data were used to force a calibrated and validated VHM model to obtain daily catchment runoff flows. The outputs were compared with the control runs at different aggregation levels. The annual scale 5 changes show decreasing flow by all GCMs when the QPM downscaled inputs are used for both periods. In case of LARS-WG mixed projections (both increasing and decreasing) are obtained. From the previous section by using the QPM downscaling, we had less annual rainfall and more annual evapotranspiration which leads to decrease in the annual flow. On the other hand, even if LARS-WG projected more rainfall in all 10 GCM runs the projected increase in evapotranspiration was also high enough to lead to decreases in the flow for three cases out of five for 2050s, while it is one out of five for 2090s.

For a detailed analysis of the flow result, the seasonal and monthly changes were examined. Figure 8 shows the monthly changes for both downscaling methods and 15 periods. This result shows how different the change signals can be by using different downscaling methods. In the QPM results the decreasing signal is dominant except in the parts of the dry months where we see increasing flows. When it comes to flows obtained based on the LARS-WG downscaled results, the decreasing signal is limited to the main rainy season and part of the short rainy season for some GCM runs while the dry season shows mainly increasing flows.

These monthly differences are related to the downscaling techniques used for the rainfall. In the QPM, the consideration of adding/removing wet days showed that the GCMs project more drier days for the future. Hence, with increasing evapotranspiration and decreasing frequency of rainfall the decreasing signal obtained for the flow 25 might be reasonable. Conversely, using the LARS-WG and QPM downscaling that excludes adding/removal of wet days, the intensity of rainfall is projected to increase (not shown). However, due to high evapotranspiration in LARS-WG the impact on the flow has a decreasing signal.
HESSD

10, 7857-7896, 2013

Influence of

downscaling

methods on extremes

\section{T. Taye and P. Willems}

Title Page

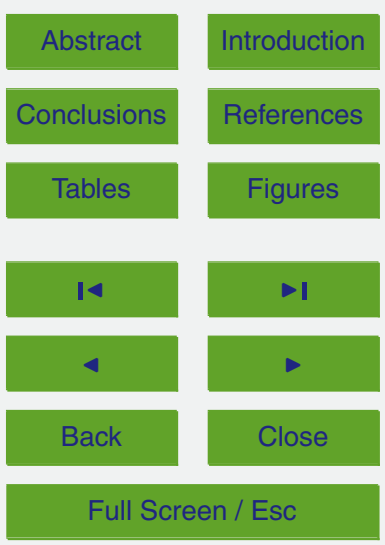

Printer-friendly Version

Interactive Discussion 
Afterwards, the daily peak flow values of the current and future period are compared using extreme value distribution plots. Figure 9 is an example of such plot in which the pattern on the peaks is shown to have similar pattern to the high rainfall intensities as was presented in Fig. 7. For instance, LARS-WG projections for 2050s shows that the 5 tail of the rainfall distribution tends to bend downwards while the observations do not show such behavior. The same effect is seen in the flow simulation results. In spite of the differences in the tail of the distribution both methods project decreasing peak flows for the future. However, when the simpler QPM approach is applied the peak flows show an increasing trend as shown in Fig. 10. Previously, when we compare the ing of wet days, the results obtained were similar and we expect similar response on the flow. However, the higher evapotranspiration from LARS-WG downscaling outputs plays a great role in decreasing the peak flows.

In general by combining A1B scenarios from five GCMs and B1 scenarios from 15 three GCMs and using the three approaches to downscale rainfall (QPM with adding/removing wet days, simpler QPM and LARS weather generator), the uncertainty on the peak flows can be summarized as in Fig. 11. Except for the highest two values most of the projections for the 2050s show decreasing peak flows. In 2090s both increasing and decreasing peak flows are projected even if most of them show a decrease. In terms of the uncertainty, the range of projections for the 2090s is wider than that for the 2050s.

\section{Discussions and conclusions}

The uncertainty related to climate change impact can be due to the climate models and/or the downscaling methods among others. Unlike the scenarios by different GCM runs that are equally probable; downscaling methods are not. Chen et al. (2011) argues that downscaling methods are not created equal and that the choice of one or more approaches should be evaluated on a case by case basis with respect to the objectives

HESSD

10, 7857-7896, 2013

Influence of

downscaling

methods on extremes

M. T. Taye and P. Willems

Title Page

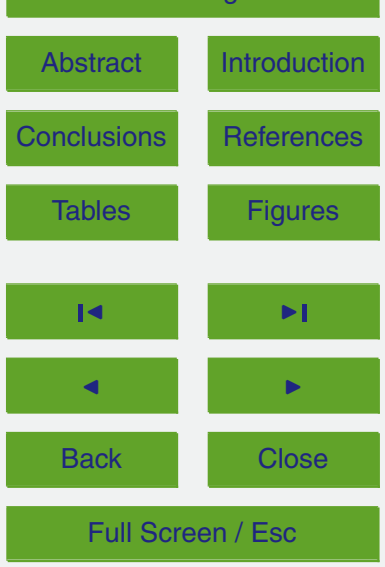

Printer-friendly Version

Interactive Discussion 
of the climate change impact study. The commonly used downscaling technique in the Blue Nile region is one of the bias correction methods. Here in this paper, methods from two statistical downscaling categories were used to investigate the impact of climate change on high rainfall and flow extremes. Although it is hardly possible to select an 5 appropriate or best downscaling method it is essential to indicate the strength and weakness of the methods used in the analysis.

The difference in downscaling was mainly concentrated on the rainfall variable. The analysis showed that although the LARS-WG generator produces good monthly statistics the extreme distribution's tail shape has some divergence from the observations.

10 This was demonstrated by comparing the observed data with the generated rainfall for the control period. It was attempted to correct the bias observed in the generated data before use in the impact analysis. However, the highest extremes still show underestimation which indicates caution has to be taken when using this method for extremes. On the other hand, the QPM downscaling produces similar extreme value distribution's tails shape. Nevertheless, the method is sensitive to the quality of the daily GCM data. The results showed that unrealistic results could be obtained when the quality of GCM's data is poor. Given acceptable quality of GCM's daily data based downscaling methods such as the QPM method presented in this paper is recommended for extreme rainfall and flow studies as it better represents the distribution's tail shape. Alternatively, when

\section{provide good enough information.}

Although the reason is dependent on the downscaling method as either decreasing rainfall or increasing evapotranspiration at seasonal scale, all the downscaling methods agree in projecting decreasing flow for the main rainy season. This gives more confidence in expecting more water shortage as a likely climate scenarios' impact trend towards the end of the century. The decrease in the flow for the 2090 horizon was also concluded in previous studies such as Beyene et al. (2010). This information is useful for the water managers of the region as this season is important for agriculture and other activities. The high uncertainty during the rest of the seasons can be an indica-

\section{HESSD}

10, 7857-7896, 2013

Influence of

downscaling

methods on extremes

M. T. Taye and P. Willems

Title Page

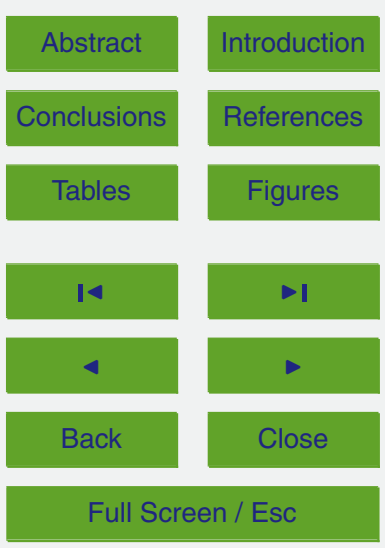

Printer-friendly Version

Interactive Discussion 
tion of the poor performance of the GCM's in capturing the rainfall or else it can be an

indication for seasonality shift.

The final number of GCMs used for the impact analysis on the flow was limited because we excluded some of the unrealistic outputs. Nevertheless, the uncertainty range 5 obtained in this paper might be greater than what is shown if more runs were used. The main information this paper provides is that the choice of the downscaling method has a stake in the estimation of climate change impacts and has to be considered the same way as we consider different GCMs to obtain the uncertainty range. The wide uncertainty range should not discourage policy makers from taking appropriate water 10 management decisions. Rather what they should take from such studies is awareness on the potential climate change impacts and attempt to find "no-regret" solutions for the proper management of the water resources under such changing conditions.

Acknowledgements. This study has been linked to FRIEND/NILE projects of UNESCO and the Flanders in Trust Fund of the Flemish Government of Belgium. The authors acknowledge 15 meteorological data provision from the National Meteorological Agency in Ethiopia. The study was financially supported by a DBOF scholarship of KU Leuven.

\section{References}

Abtew, W., Melesse, A. M., and Dessalegne, T.: El Niño Southern Oscillation link to the Blue Nile River Basin hydrology, Hydrol. Process., 23, 3653-3660, 2009.

Arnbjerg-Nielsen, K.: Quantification of climate change effects on extreme precipitation used for high resolution hydrologic design, Urban Water J., 9, 57-65, 2012.

Beyene, T., Lettenmaier, D. P., and Kabat, P.: Hydrologic impacts of climate change on the Nile River Basin: implications of the 2007 IPCC scenarios, Climatic Change, 100, 433-461, 2010.

Camberlin, P.: Rainfall anomalies in the source region of the Nile and their connection with the Indian summer monsoon, J. Climate, 10, 1380-1392, 1996.

Chen, J., Brissette, F. P., and Leconte, R.: Uncertainty of downscaling method in quantifying the impact of climate change on hydrology, J. Hydrol., 401, 190-202, 2011.

Influence of

downscaling

methods on extremes

M. T. Taye and P. Willems

Title Page

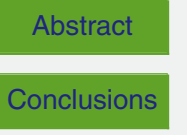

Tables

Figures

14

$\rightarrow 1$

4

Back

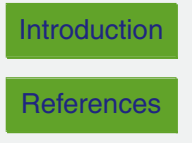

Close

Full Screen / Esc

Printer-friendly Version

Interactive Discussion 
Dinku, T., Chidzambwa, S., Ceccato, P., Connor, S. J., and Ropelewski, C. F.: Validation of highresolution satellite rainfall products over complex terrain, Int. J. Remote Sens., 29, 40974110, 2008.

Diro, G., Grimes, D. I. F., and Black, E.: Teleconnections between Ethiopian summer rainfall and 5 sea surface temperature?: part I - observation and modelling. Clim. Dynam. 37, 121-131, 2010.

Ebrahim, G. Y., Jonoski, A., van Griensven, A., and Baldassarre, G. Di.: Downscaling technique uncertainty in assessing hydrological impact of climate change in the Upper Beles River Basin, Ethiopia, Hydrol. Res., 44, 377-398, 2013.

10 Elshamy, M. E., Seierstad, I. A., and Sorteberg, A.: Impacts of climate change on Blue Nile flows using bias-corrected GCM scenarios, Hydrol. Earth Syst. Sci., 13, 551-565, doi:10.5194/hess-13-551-2009, 2009.

Fowler, H., Blenkinsop, S., and Tebaldi, C.: Linking climate change modelling to impacts studies: recent advances in downscaling techniques for hydrological modelling, Int. J. Climatol., 27, 15 1547-1578, 2007.

IPCC: Climate Change 2007, in: Impacts, Adaptation and Vulnerability, Contribution of Working Group II to the Fourth Assessment Report of the Intergovernmental Panel on Climate Change (IPCC), edited by: Parry, M. L., Canziani, O. F., Palutikof, J. P., van der Linden, P. J., and Hanson, C. E., Cambridge University Press, Cambridge, UK, 1000 pp., 2007.

20

IPCC: Managing the Risks of Extreme Events and Disasters to Advance Climate Change Adaptation, edited by: Field,C. B., Barros, V., Stocker, T. F., and Dahe, Q., Cambridge University Press, Cambridge, UK and New York, USA, 582 pp., 2012.

Jury, M. R.: Ethiopian decadal climate variability, Theor. Appl. Climatol., 101, 29-40, 2010.

$\mathrm{Kim}, \mathrm{U}$. and Kaluarachchi, J. J.: Climate change impacts on water resources in the Upper Blue Nile River Basin, Ethiopia, J. Am. Water Resour. Assoc., 45, 1361-1378, 2009.

Liu, T., Willems, P., Pan, X. L., Bao, An. M., Chen, X., Veroustraete, F., and Dong, Q. H.: Climate change impact on water resource extremes in a headwater region of the Tarim basin in China, Hydrol. Earth Syst. Sci., 15, 3511-3527, doi:10.5194/hess-15-3511-2011, 2011.

Melesse, A., Abtew, W., Dessalegne, T., and Wang, X.: Low and high flow analyses and wavelet 30 application for characterization of the Blue Nile River system, Hydrol. Process., 24, 241-252, 2010.

Nawaz, R., Bellerby, T., Sayed, M., and Elshamy, M.: Blue Nile runoff sensitivity to climate change, Open Hydrol. J., 4, 137-151, 2010.

\section{HESSD}

10, 7857-7896, 2013

Influence of

downscaling

methods on extremes

M. T. Taye and P. Willems

Title Page

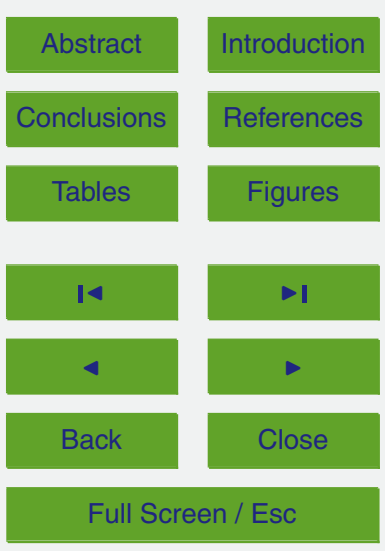

Printer-friendly Version

Interactive Discussion 
Nyeko-Ogiramoi, P., Ngirane-Katashaya, G., Willems, P., and Ntegeka, V.: Evaluation and intercomparison of Global Climate Models' performance over Katonga and Ruizi catchments in Lake Victoria basin, Phys. Chem. Earth, 35, 618-633, 2010.

Semenov, M. and Stratonovitch, P.: Use of multi-model ensembles from global climate models 5 for assessment of climate change impacts, Clim. Res., 41, 1-14, 2010.

Setegn, S. G., Rayner, D., Melesse, Assefa, M., Bijan, D., and Raghavan, S.: Impact of climate change on the hydroclimatology of Lake Tana Basin, Ethiopia, Water Resour. Res., 47, W04511, doi:10.1029/2010WR009248, 2011.

Sunyer, M. A., Madsen, H., and Ang, P. H.: A comparison of different regional climate models and statistical downscaling methods for extreme rainfall estimation under climate change, Atmos. Res., 103, 119-128, 2012.

Taye, M. T. and Willems, P.: Temporal variability of hydroclimatic extremes in the Blue Nile basin, Water Resour. Res., 48, 1-14, 2012.

Taye, M. T., Ntegeka, V., Ogiramoi, N. P., and Willems, P.: Assessment of climate change impact 15 on hydrological extremes in two source regions of the Nile River Basin, Hydrol. Earth Syst. Sci., 15, 209-222, doi:10.5194/hess-15-209-2011, 2011.

Teutschbein, C., Wetterhall, F., and Seibert, J.: Evaluation of different downscaling techniques for hydrological climate-change impact studies at the catchment scale, Clim. Dynam. 37, 2087-2105, 2011.

20 Van Steenbergen, N. and Willems, P.: Method for testing the accuracy of rainfall-runoff models in predicting peak flow changes due to rainfall changes, in a climate changing context, J. Hydrol., 414-415, 425-434, 2011.

Wilby, R. L. and Dawson, C. W.: SDSM 4.2 - A decision support tool for the assessment of regional climate change impacts User Manual, Leicestershire, UK, 2007.

Wilby, R. L. and Wigley, T. M. L.: Downscaling general circulation model output: a review of methods and limitations, Progress Phys. Geogr., 21, 530-548, 1997.

Wilby, R. L., Dawson, C. W., and Barrow, E.: SDSM - a decision support tool for the assessment of regional climate change impacts, Environ. Modell. Softw., 17, 145-157, 2002.

Willems, P.: A time series tool to support the multi-criteria performance evaluation of rainfallrunoff models, Environ. Modell. Softw., 24, 311-321, 2009.

Willems, P.: Parsimonious rainfall-runoff model construction supported by time series processing and validation of hydrological extremes, J. Hydrol., in review, 2013.
Influence of

downscaling

methods on extremes

M. T. Taye and P. Willems

Title Page

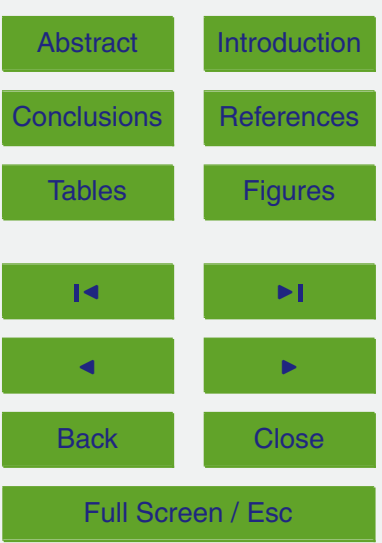

Printer-friendly Version

Interactive Discussion 
Willems, P. and Vrac, M.: Statistical precipitation downscaling for small-scale hydrological impact investigations of climate change, J. Hydrol., 402, 193-205, 2011.

Willems, P., Olsson, J., Arnbjerg-Nielsen, K., Beecham, S., Pathirana, A., Gregersen, I. B., Madsen, H., and Nguyen, V. T. V.: Impacts of Climate Change on Rainfall Extremes and Urban Drainage Systems, IWA Publishing Company, London, UK, 238 pp., 2012.

Zaitchik, B. F., Simane, B., Habib, S., Anderson, M. C., Ozdogan, M., and Foltz, J. D.: Building climate resilience in the Blue Nile/Abay Highlands: a role for Earth system sciences, Int. J. Environ. Res. Pub. Health, 9, 435-461, 2012.

\section{HESSD}

10, 7857-7896, 2013

Influence of

downscaling

methods on extremes

M. T. Taye and P. Willems

Title Page

Abstract

Introduction

Conclusions

References

Tables

Figures

14

4

Back

Full Screen / Esc

Printer-friendly Version

Interactive Discussion 


\section{HESSD}

10, 7857-7896, 2013

Influence of

downscaling

Table 1. Selected GCM runs for impact analysis, model acronym source is from Semenov and Stratonovitch (2010).

\begin{tabular}{|c|c|c|c|}
\hline Research Centre and Country & $\begin{array}{l}\text { Global climate } \\
\text { model }\end{array}$ & $\begin{array}{l}\text { Model } \\
\text { acronym }\end{array}$ & $\begin{array}{l}\text { Grid } \\
\text { resolution }\end{array}$ \\
\hline $\begin{array}{l}\text { Commonwealth Scientific and Industrial Research } \\
\text { Organization, Australia }\end{array}$ & CSIRO-MK3.0 & CSMK3 & $1.9 \times 1.9^{\circ}$ \\
\hline $\begin{array}{l}\text { Canadian Centre for Climate Modelling and } \\
\text { Analysis, Canada }\end{array}$ & CGCM33.1 (T47) & CGMR & $2.8 \times 2.8^{\circ}$ \\
\hline $\begin{array}{l}\text { Centre National de Recherches Météorologiques, } \\
\text { France }\end{array}$ & CNRM-CM3 & CNCM3 & $1.9 \times 1.9^{\circ}$ \\
\hline Institute Pierre Simon Laplace, France & IPS & $\mid \mathrm{PCI}$ & $2.5 \times 3.75^{\circ}$ \\
\hline & & & $2.8^{\circ}$ \\
\hline Instit & IN & IN & $4 \times 5^{\circ}$ \\
\hline Max-Planck Institute for Meteorology, Germany & ECHAM5-OM & MPEH5 & $1.9 \times 1.9^{\circ}$ \\
\hline National Institute for Environmental Studies, Jap & MRI-CGCM2.3.2 & MIHR & $2.8 \times 2.8^{\circ}$ \\
\hline & & & $2.0 \times 2.5^{\circ}$ \\
\hline Goddard Institute for Space Studies, USA & GISS-AOM & GIAOM & $3 \times 4^{\circ}$ \\
\hline
\end{tabular}

methods on extremes

M. T. Taye and P. Willems

Title Page

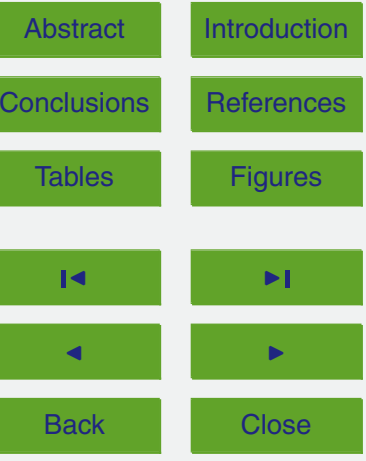

Full Screen / Esc

Printer-friendly Version

Interactive Discussion 
Table 2. Mean annual rainfall projection given in percentage change using QPM and LARS-WG for 2050s and 2090s.

\begin{tabular}{llrrrrr}
\hline & & \multicolumn{2}{c}{ QPM } & & \multicolumn{2}{c}{ LARS } \\
\cline { 3 - 4 } \cline { 6 - 7 } & & 2050s & 2090s & & 2050s & 2090s \\
\hline 1. & CNCM3 & 19.86 & 21.46 & & 32.75 & 40.17 \\
2. & GIAOM & -4.08 & -9.60 & & 15.46 & 23.42 \\
3. & CGMR & -7.86 & -23.54 & & 10.89 & 27.09 \\
4. & FGOALS & -7.48 & -16.92 & & 33.03 & 53.79 \\
5. & IPCM4 & -9.69 & -13.43 & & 20.78 & 44.83 \\
\hline
\end{tabular}

\section{HESSD}

10, 7857-7896, 2013

\section{Influence of}

downscaling

methods on extremes

M. T. Taye and P. Willems

Title Page

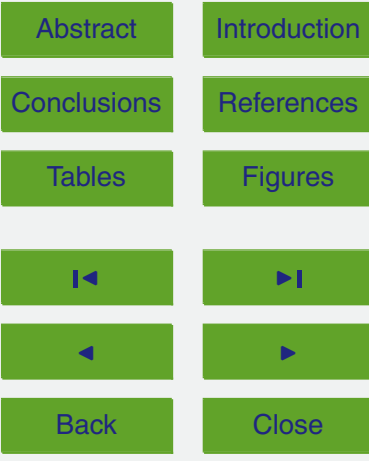

Full Screen / Esc

Printer-friendly Version

Interactive Discussion 
Table 3. Mean seasonal rainfall projection given in percentage change using QPM and LARSWG for 2050s and 2090s.

\begin{tabular}{|c|c|c|c|c|c|c|c|c|c|}
\hline & & \multicolumn{4}{|c|}{ JJAS } & \multicolumn{4}{|c|}{ MAM } \\
\hline & & \multicolumn{2}{|c|}{ QPM } & \multicolumn{2}{|c|}{ LARS } & \multicolumn{2}{|c|}{ QPM } & \multicolumn{2}{|c|}{ LARS } \\
\hline & & $2050 s$ & 2090s & $2050 s$ & 2090s & 2050s & $2090 s$ & $2050 s$ & 2090s \\
\hline 1. & CNCM3 & -6.61 & -6.13 & 0.67 & 4.10 & -27.59 & -31.07 & -5.67 & -7.75 \\
\hline 2. & GIAOM & -9.54 & -3.44 & -5.38 & 7.13 & -18.55 & -28.26 & 14.75 & 22.78 \\
\hline 3. & CGMR & -12.26 & -20.76 & -10.23 & -15.88 & -62.76 & -62.02 & -28.89 & -23.38 \\
\hline 4. & FGOALS & -2.05 & -1.54 & -0.25 & 5.30 & -52.22 & -55.75 & 3.34 & 15.50 \\
\hline 5. & IPCM4 & -1.08 & -2.75 & 1.80 & 1.85 & -42.31 & -47.25 & 3.45 & 3.55 \\
\hline
\end{tabular}

\section{HESSD}

10, 7857-7896, 2013

Influence of

downscaling

methods on extremes

M. T. Taye and P. Willems

Title Page

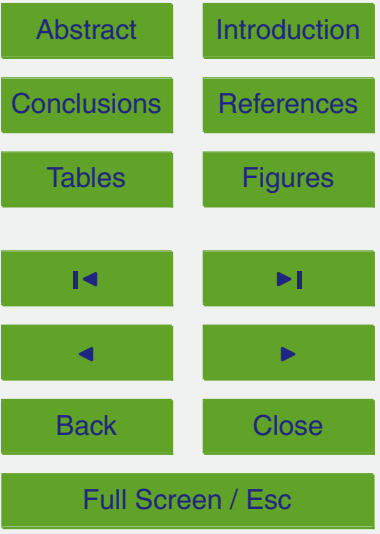

Printer-friendly Version

Interactive Discussion 
Table 4. Mean annual absolute maximum and minimum temperature change $\left({ }^{\circ} \mathrm{C}\right)$ using QPM and LARS-WG for 2050s and 2090s.

\begin{tabular}{|c|c|c|c|c|c|c|c|c|c|}
\hline & \multicolumn{4}{|c|}{ Tmax } & \multicolumn{4}{|c|}{ Tmin } \\
\hline & & \multicolumn{2}{|c|}{ QPM } & \multicolumn{2}{|c|}{ LARS } & \multicolumn{2}{|c|}{ QPM } & \multicolumn{2}{|c|}{ LARS } \\
\hline & & $2050 s$ & $2090 s$ & $2050 s$ & $2090 s$ & $2050 s$ & 2090s & $2050 s$ & 2090s \\
\hline 1. & CNCM3 & 1.71 & 2.69 & 2.33 & 3.37 & 2.69 & 3.78 & 2.33 & 3.37 \\
\hline 2. & GIAOM & 1.24 & 2.06 & 1.30 & 2.06 & 1.53 & 2.38 & 1.55 & 2.39 \\
\hline 3. & CGMR & 2.21 & 3.00 & 2.47 & 3.38 & 2.33 & 3.27 & 2.48 & 3.39 \\
\hline 4. & FGOALS & 1.22 & 1.85 & 1.44 & 2.22 & 1.21 & 2.28 & 1.45 & 2.23 \\
\hline 5. & IPCM4 & 1.85 & 2.76 & 2.36 & 4.04 & 2.69 & 4.65 & 2.36 & 4.04 \\
\hline
\end{tabular}

HESSD

10, 7857-7896, 2013

Influence of

downscaling

methods on extremes

M. T. Taye and P. Willems

Title Page

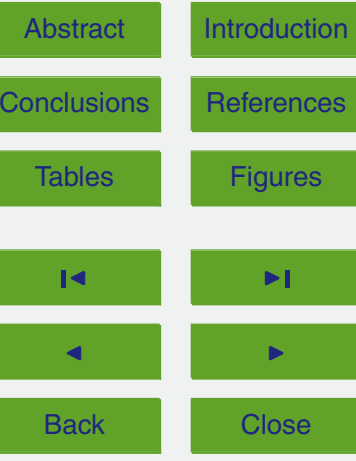

Full Screen / Esc

Printer-friendly Version

Interactive Discussion 
Table 5. Mean annual evapotranspiration projections given in percentage change using QPM and LARS-WG for 2050s and 2090s.

\begin{tabular}{llrrrrr}
\hline & & \multicolumn{2}{c}{ QPM } & & \multicolumn{2}{c}{ LARS } \\
\cline { 3 - 3 } \cline { 6 - 7 } & & $2050 \mathrm{~s}$ & $2090 \mathrm{~s}$ & & $2050 \mathrm{~s}$ & $2090 \mathrm{~s}$ \\
\hline 1. & CNCM3 & 2.31 & 4.72 & & 7.14 & 10.17 \\
2. & GIAOM & 2.67 & 4.74 & & 3.43 & 5.36 \\
3. & CGMR & 5.89 & 8.19 & & 7.50 & 10.10 \\
4. & FGOALS & 3.20 & 3.99 & & 4.56 & 6.79 \\
5. & IPCM4 & 2.63 & 1.61 & & 7.21 & 12.05 \\
\hline
\end{tabular}

\section{HESSD}

10, 7857-7896, 2013

Influence of

downscaling

methods on extremes

M. T. Taye and P. Willems

Title Page

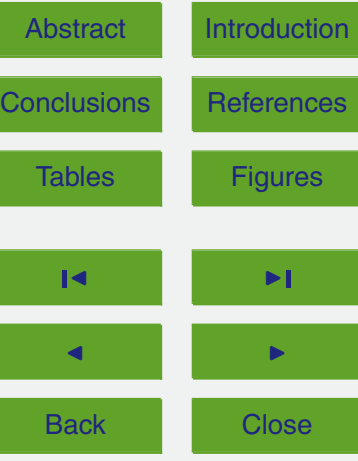

Full Screen / Esc

Printer-friendly Version

Interactive Discussion 
Table 6. Mean annual flow projections given in percentage change using QPM and LARS-WG for 2050s and 2090s.

\begin{tabular}{llrrrrr}
\hline & & \multicolumn{2}{c}{ QPM } & & \multicolumn{2}{c}{ LARS } \\
\cline { 3 - 4 } \cline { 6 - 7 } \cline { 5 - 6 } & & $2050 \mathrm{~s}$ & $2090 \mathrm{~s}$ & & $2050 \mathrm{~s}$ & $2090 \mathrm{~s}$ \\
\hline 1. & CNCM3 & -1.87 & -5.99 & & 2.67 & 7.57 \\
2. & GIAOM & -23.21 & -20.65 & & -6.49 & 5.26 \\
3. & CGMR & -33.07 & -41.45 & & -18.05 & -12.95 \\
4. & FGOALS & -24.14 & -19.48 & & 1.45 & 21.07 \\
5. & IPCM4 & -19.91 & -24.67 & & -4.60 & 5.95 \\
\hline
\end{tabular}

\section{HESSD}

10, 7857-7896, 2013

Influence of

downscaling

methods on extremes

M. T. Taye and P. Willems

Title Page

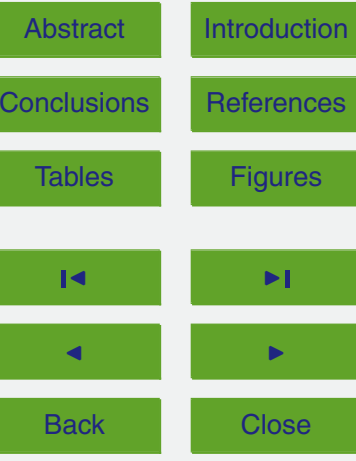

Full Screen / Esc

Printer-friendly Version

Interactive Discussion 


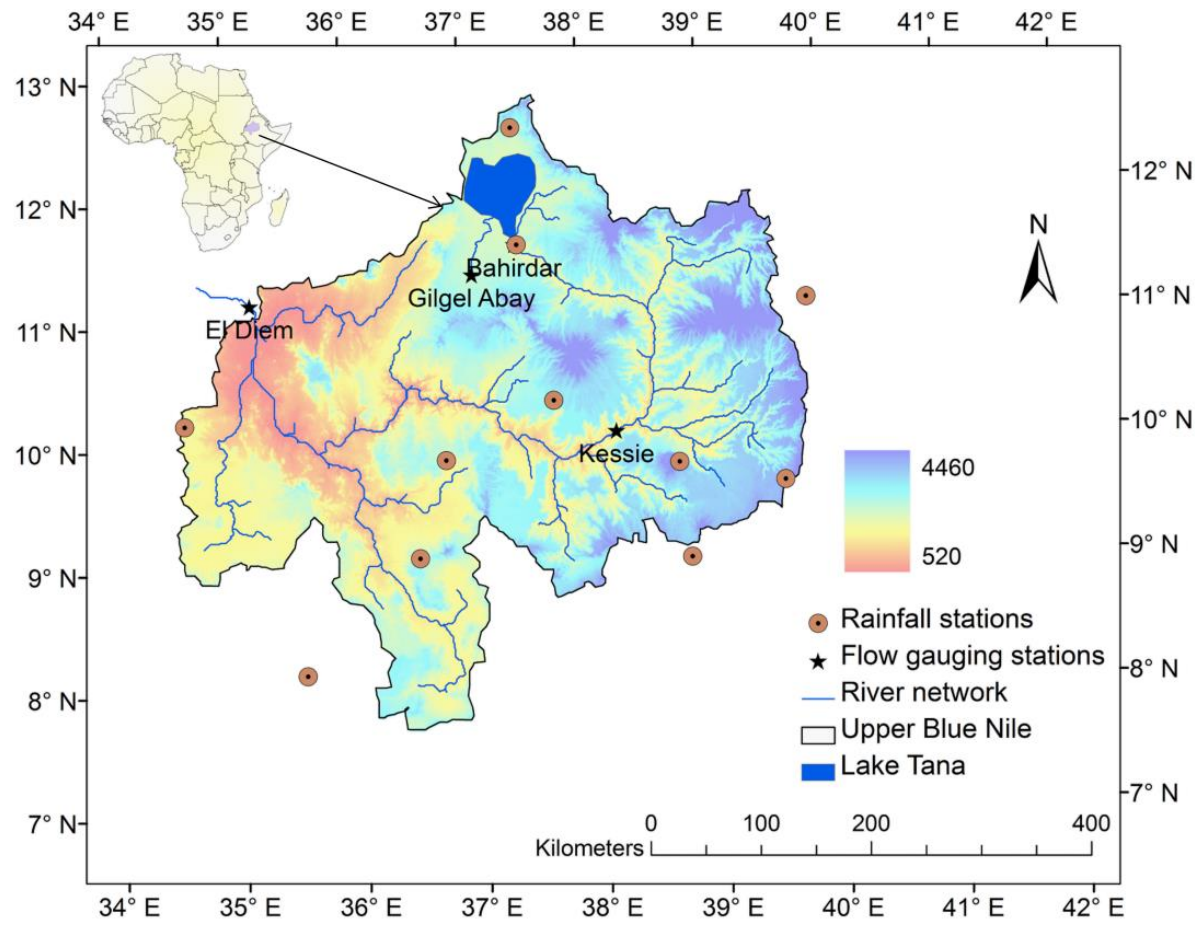

\section{HESSD}

10, 7857-7896, 2013

\section{Influence of downscaling}

methods on extremes

M. T. Taye and P. Willems

Title Page

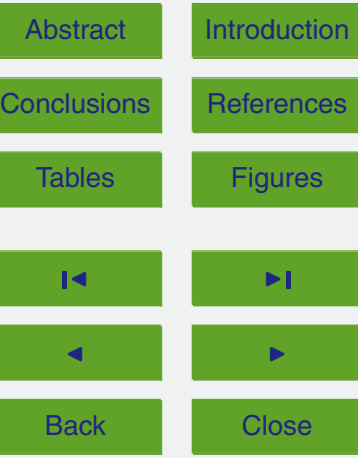

Full Screen / Esc

Fig. 1. Location of the upper Blue Nile basin.

Printer-friendly Version

Interactive Discussion 

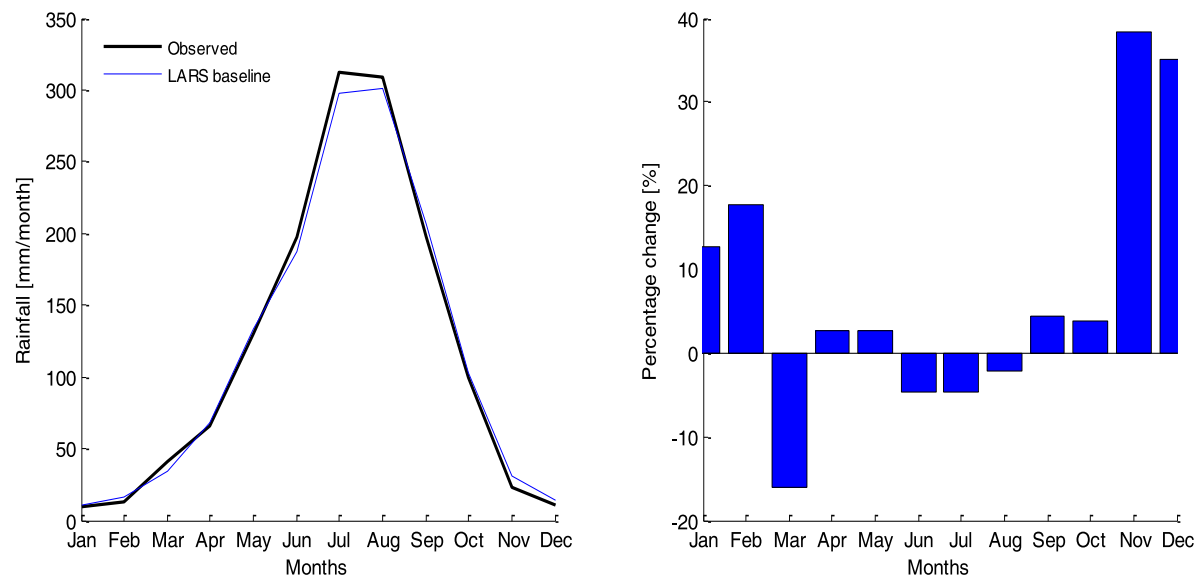

HESSD

10, 7857-7896, 2013

Influence of

downscaling

methods on extremes

M. T. Taye and P. Willems

Title Page

Abstract

Introduction

Conclusions

References

Tables

Figures

14

Fig. 2. Mean monthly rainfall of observed and LARS-WG generated baseline (left) and percentage change of LARS-WG baseline series in comparison with the observed data for the control period.

\section{4}

Back
Close

Full Screen / Esc

Printer-friendly Version

Interactive Discussion 


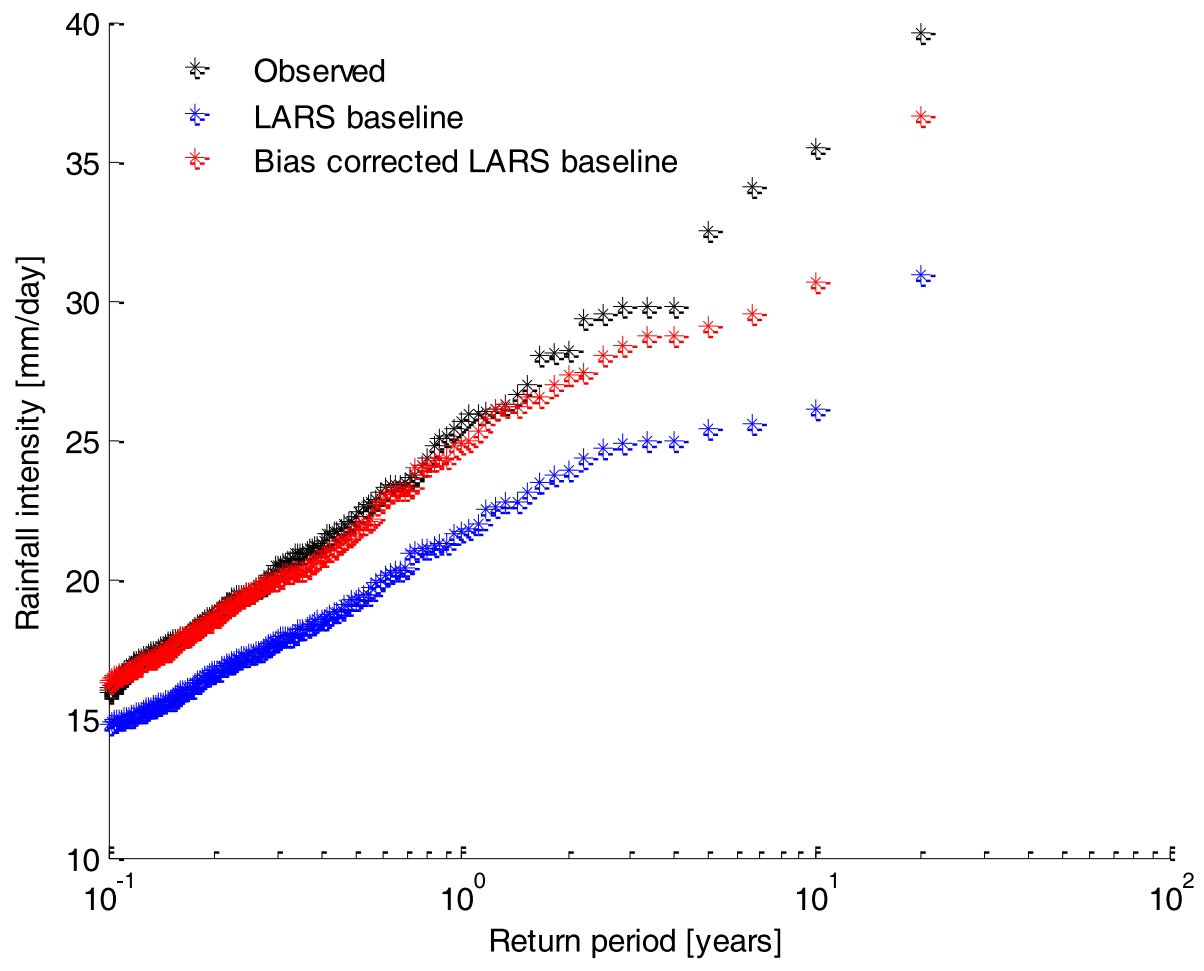

Fig. 3. Comparison of peak rainfall intensities for observation and LARS-WG generated data before and after bias correction.

\section{HESSD}

10, 7857-7896, 2013

\section{Influence of} downscaling

methods on extremes

M. T. Taye and P. Willems

Title Page

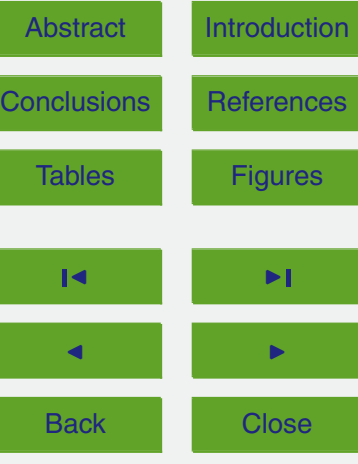

Full Screen / Esc

Printer-friendly Version

Interactive Discussion 


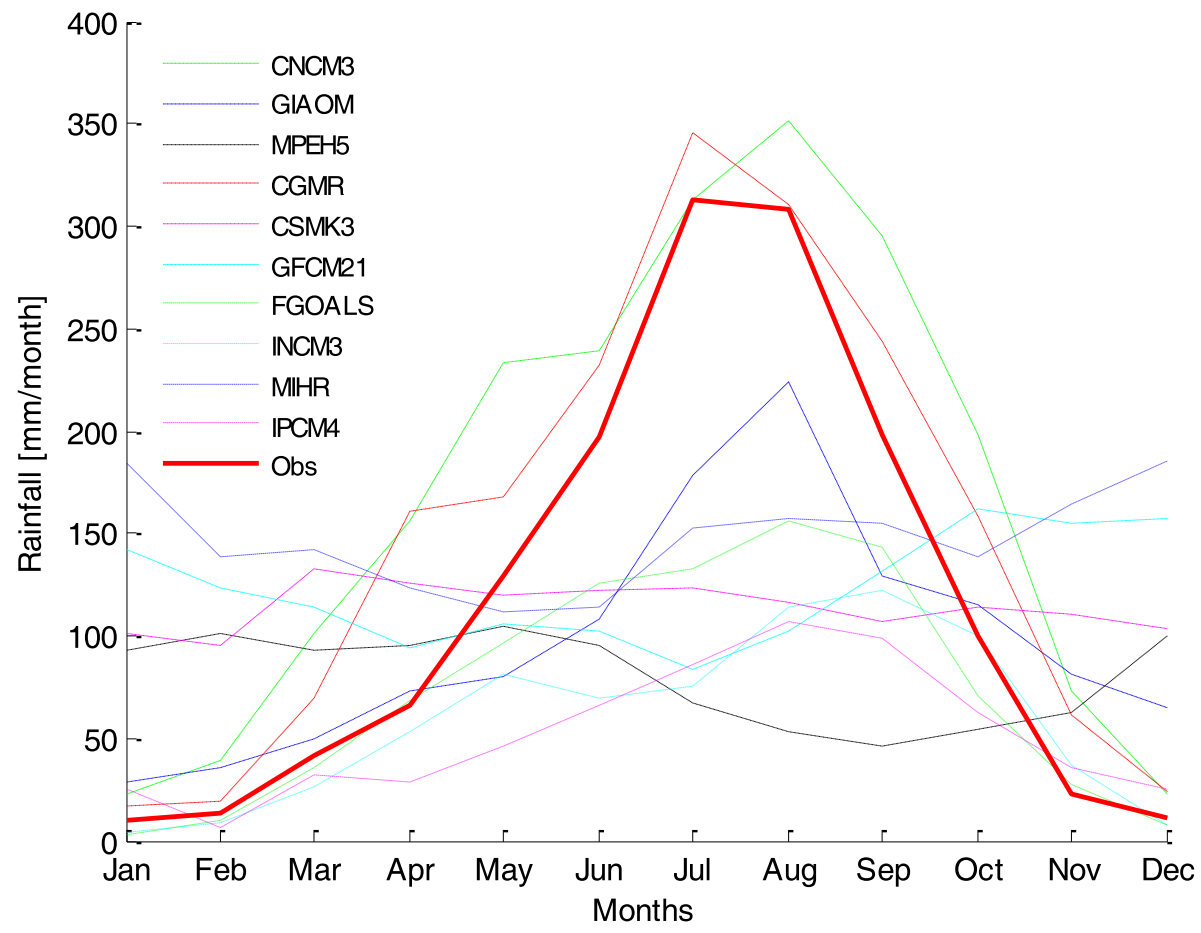

\section{HESSD}

10, 7857-7896, 2013

Influence of downscaling

methods on extremes

M. T. Taye and P. Willems

Title Page



Full Screen / Esc

Fig. 4. Monthly performance of 10 the GCM runs for the control period.

Printer-friendly Version

Interactive Discussion 


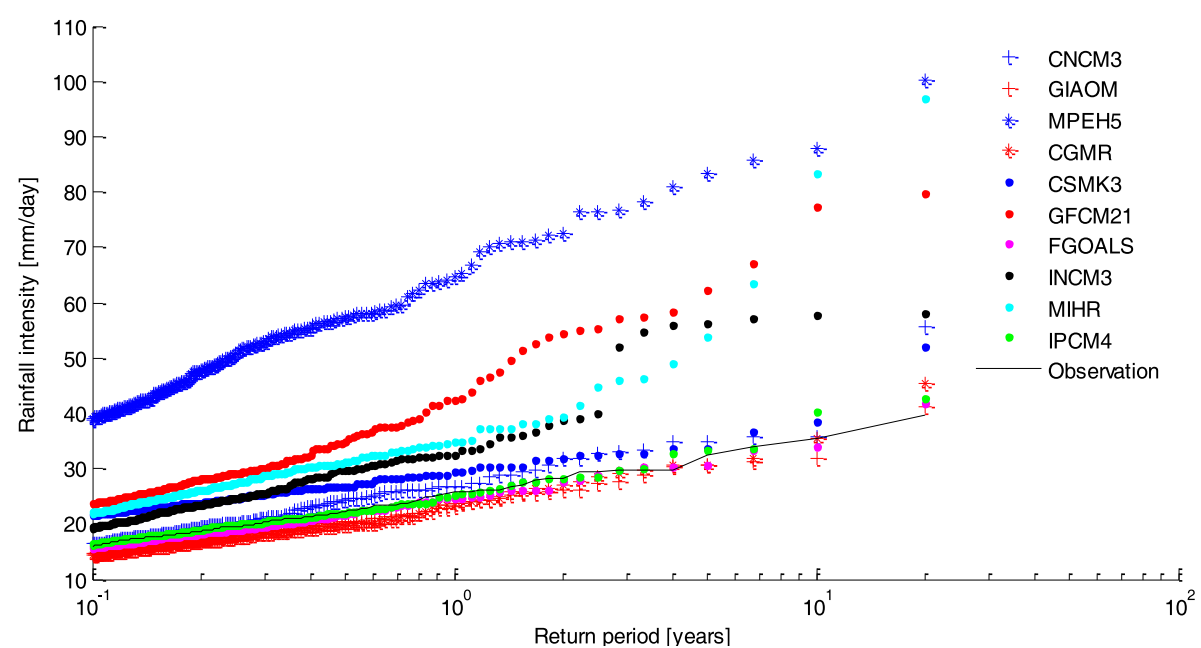

Fig. 5. Example of projected rainfall using the quantile perturbation method for 2050 s and A1B scenario.

\section{HESSD}

$10,7857-7896,2013$

\section{Influence of downscaling}

\section{methods on extremes}

M. T. Taye and P. Willems

Title Page

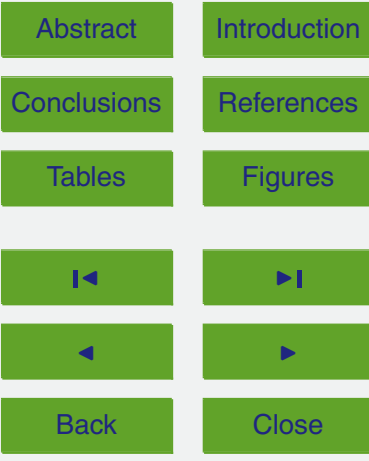

Full Screen / Esc

Printer-friendly Version

Interactive Discussion 

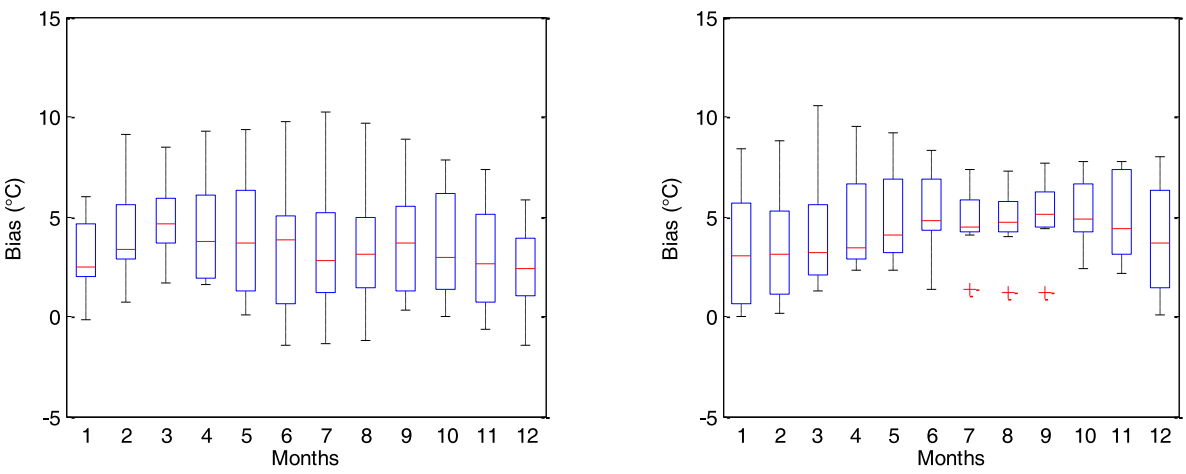

\section{HESSD}

10, 7857-7896, 2013

\section{Influence of} downscaling

methods on extremes

M. T. Taye and P. Willems

Title Page

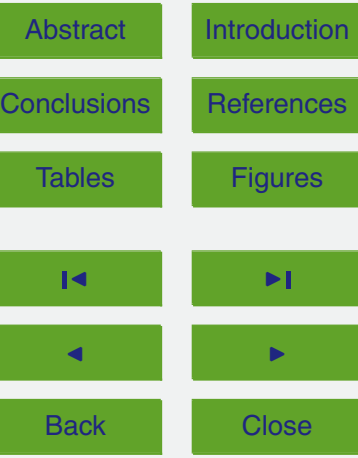

Full Screen / Esc

Printer-friendly Version

Interactive Discussion 


\section{HESSD}

10, 7857-7896, 2013
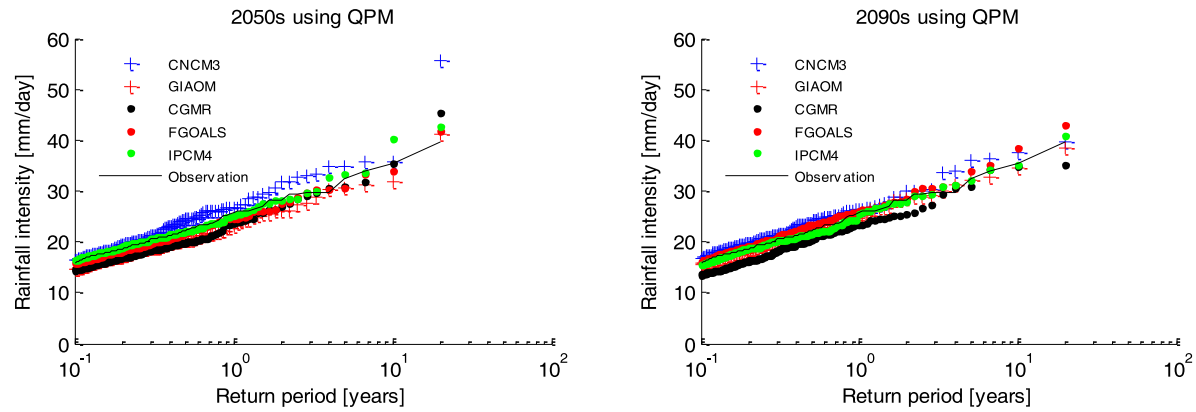

\section{Influence of downscaling}

methods on extremes

M. T. Taye and P. Willems

Title Page
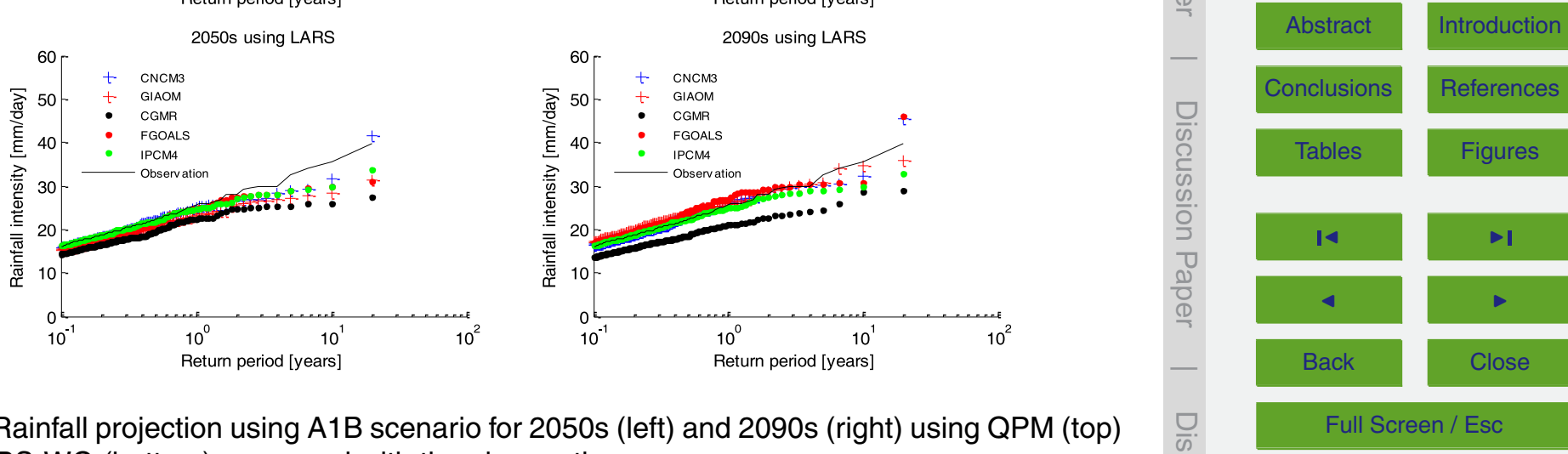

and LARS-WG (bottom) compared with the observations.

Printer-friendly Version

Interactive Discussion 

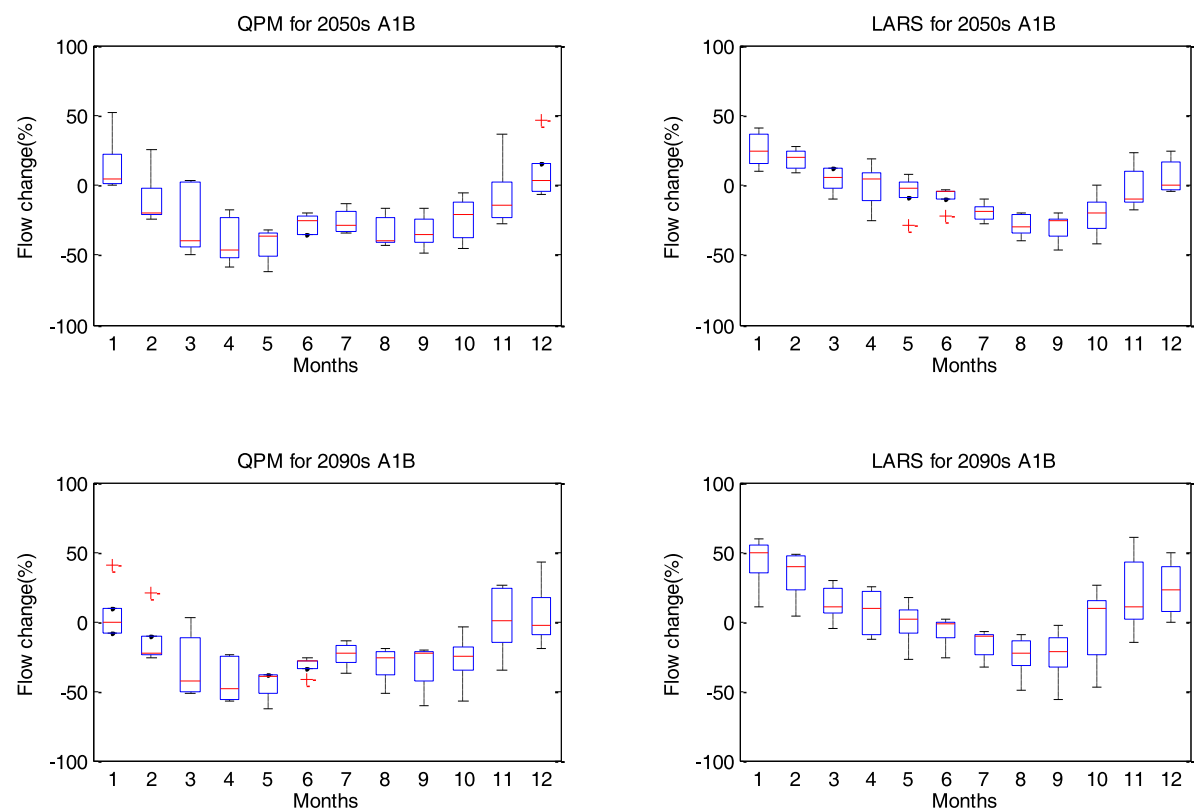

\section{HESSD}

10, 7857-7896, 2013

\section{Influence of} downscaling

methods on extremes

M. T. Taye and P. Willems

Title Page

4

\section{Full Screen / Esc}

Fig. 8.
WG (right). 


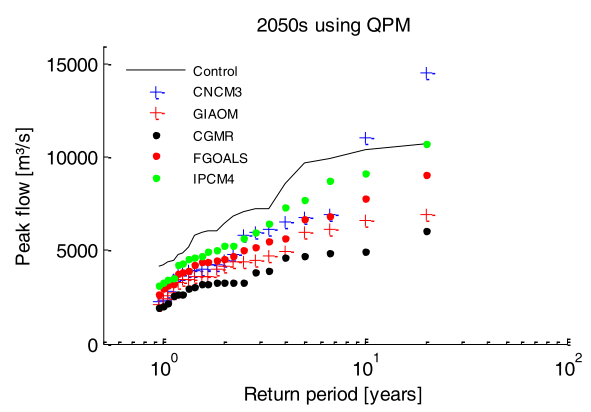

2090s using QPM

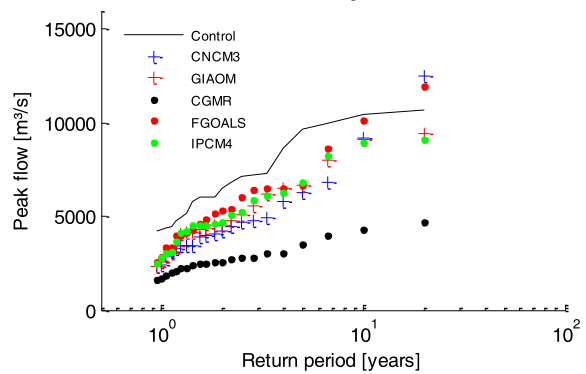

2050s using LARS

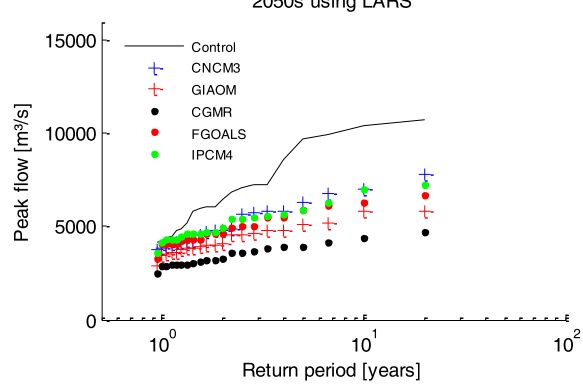

2090s using LARS

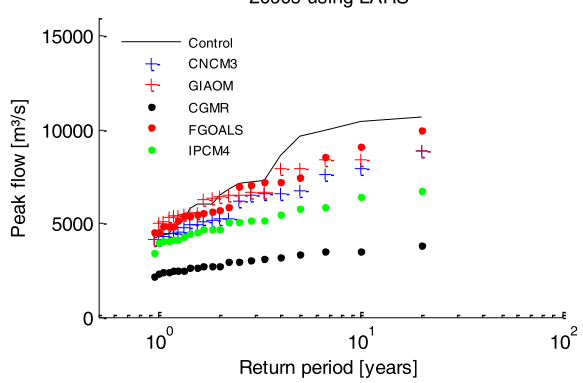

HESSD

10, 7857-7896, 2013

\section{Influence of}

downscaling

methods on extremes

M. T. Taye and P. Willems

Title Page

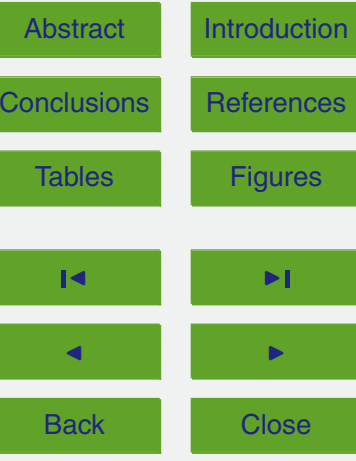

Full Screen / Esc

Printer-friendly Version

Interactive Discussion 

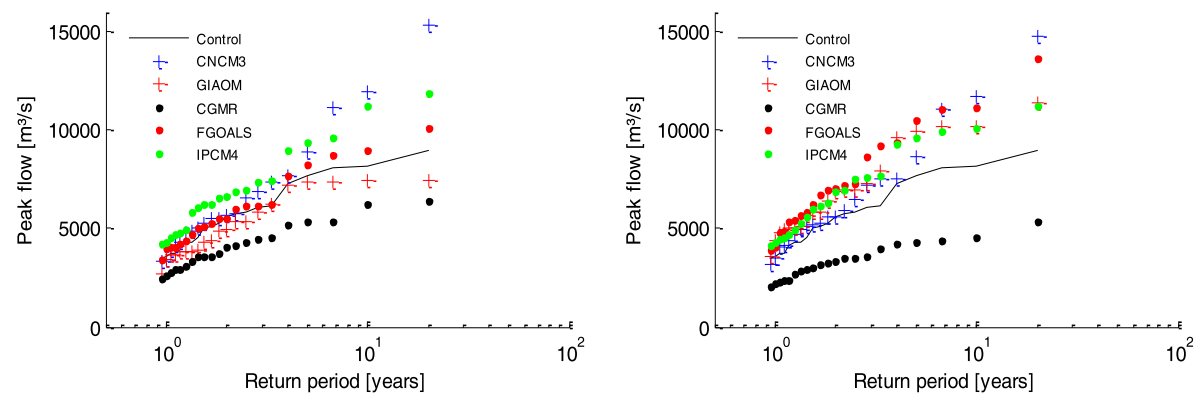

\section{HESSD}

10, 7857-7896, 2013

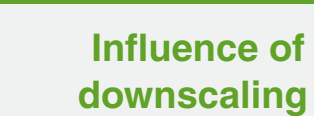

methods on extremes

M. T. Taye and P. Willems

Title Page

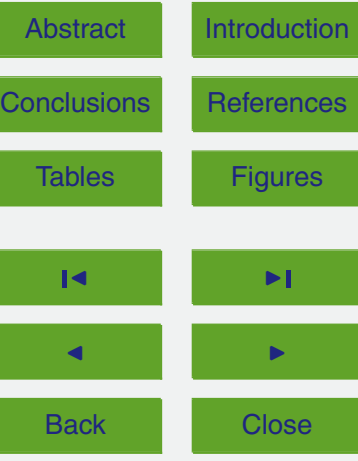

Full Screen / Esc

Printer-friendly Version

Interactive Discussion 

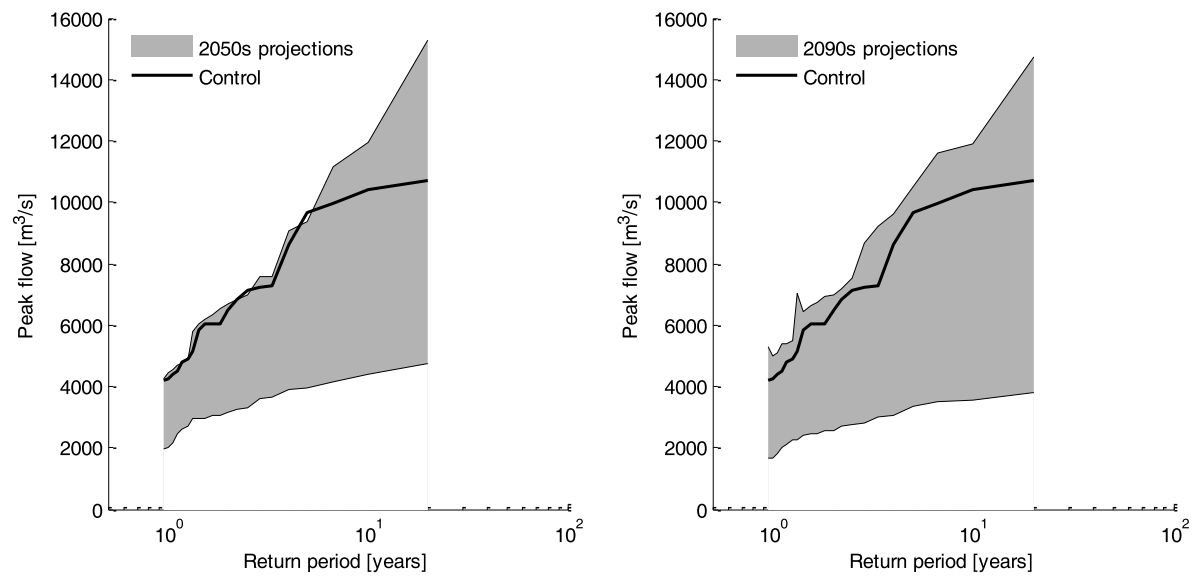

\section{HESSD}

10, 7857-7896, 2013

\section{Influence of downscaling}

methods on extremes

M. T. Taye and P. Willems

Title Page

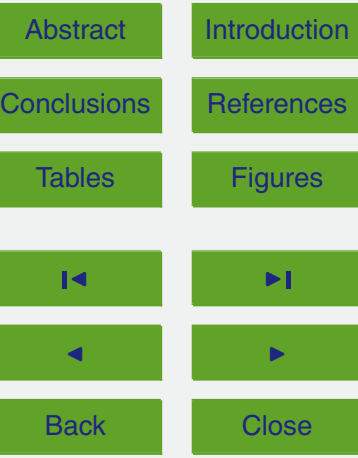

Full Screen / Esc

Printer-friendly Version

Interactive Discussion 